\title{
Variations
}

Variations

Revue internationale de théorie critique

15 | 2011

La haine

\section{Une cartographie inventive mais limitée}

\section{Didier Epsztajn}

\section{OpenEdition}

\section{Journals}

Édition électronique

URL : http://journals.openedition.org/variations/110

DOI : 10.4000/variations. 110

ISSN : 1968-3960

\section{Éditeur}

Les amis de Variations

Édition imprimée

Date de publication : 1 mars 2011

\section{Référence électronique}

Didier Epsztajn, « Une cartographie inventive mais limitée », Variations [En ligne], 15 | 2011, mis en ligne le 01 février 2012, consulté le 22 septembre 2020. URL : http://journals.openedition.org/variations/ 110 ; DOI : https://doi.org/10.4000/variations. 110 
Didier Epsztajn

Note de lecture

Une cartographie inventive mais limitée

A propos de Razmig Keucheyan: Hémisphère Gauche. Une cartographie des nouvelles pensées critiques

(Editions Zones, Paris 2010)

«La conjoncture historique dans laquelle se forment des théories leur imprime leurs principales caractéristiques. » Certes, mais ce qui est vrai pour les "théoriciens" l'est tout aussi pour ceux et celles qui les interrogent. Il faudrait pour les un-e-s et les autres, ne jamais oublier de préciser leur insertion dans le champ social et politique. Ceci n'est pas une mauvaise querelle, mais il me semble qu'il convient toujours de se situer lorsque l'on travaille sur ces sujets, ou comme le disait Léo Thiers-Vidal «je ne peux nier ma position sociale et sa détermination sur mon rapport au monde et aux autres. »

Razmig Keucheyan situe les nouvelles théories «nouvelles en ceci qu'elles sont apparues après la chute du mur de Berlin ». L'auteur pose, à très juste titre «Tout commence par une défaite ». Le livre est divisé en trois parties « Contextes », « Système » et « Sujets ».

Sans forcément partager les analyses de l'auteur, je souligne l'intérêt du premier chapitre « $L a$ défaite de la pensée critique (1977-1993) » : sa périodisation; sa géographie des pensées critiques ; son insistance sur le fait que les élaborations de nombreux « marxistes occidentaux » se sont faites, contrairement aux époques précédentes, hors des organisations du mouvement ouvrier et donc 
souvent « sans rapports directs avec la stratégie politique »; le foisonnement des références.

Puis l'auteur poursuit par une « Brève histoire de la Nouvelle gauche, 1953-1977 » riche de nombreuses références (débats et auteurs), mais sous estimant cependant les lieux de débats non universitaires.

Razmig Keucheyan tente une typologie des intellectuels critiques contemporains : les convertis, les pessimistes, les résistants, les novateurs, les experts, les dirigeants. Ce classement permet de d'aborder des parcours variés, de souligner l'internationalisation des pensées critiques et l'introduction de nouveaux objets d'analyse.

Je ne ferais pas querelle ni des regroupements, ni même de la présence de certains, que je juge un peu incongrue. Il ne suffit pas de «prendre le contre-pied du discours dominant» pour élaborer une pensée critique. Les choix des uns et des autres furent souvent, comme le souligne l'auteur, peu « en prise avec les processus politiques réels », voir en opposition aux mouvements concrets d'émancipation.

A l'inverse, les milieux militants, "partisans" ou "associatifs", oubliés dans cette géographie, furent des lieux de confrontations, d'élaborations, à commencer par celles des «féministes radicales» ou des «féministes luttes de classes», d'une richesse qui vaut bien celle de X ou Y. Je pourrais aussi citer les élaborations, encore que fortes incomplètes, sur l'autogestion ou la démocratie radicale. En prise avec des revendications sociales et politiques, elles furent et restent porteuses d'une subversion potentielle, ce qui n'est pas le cas de toutes les nouvelles pensées critiques.

Quoiqu'il en soit, comme je le souligne en «éditorial» du blog : la pensée émancipatrice fait trop souvent l'impasse sur certains domaines et reste encore souvent plombée par l'économisme. La vulgate marxiste, les réductions sociologiques, les lectures sans sexe/genre, sans classe et sans espérance dominent trop souvent, pour que les lectrices et les lecteurs ne soient pas 
plus attentives ou soucieuses (graphie volontaire) des recherches iconoclastes, des démarches exploratrices, non abouties ou des interrogations sur les sentiers plus ou moins fréquentés.

Le travail de Razmig Keucheyan correspond à cette aspiration, il est de plus très clair et agréable à lire.

La seconde partie de l'ouvrage est consacrée aux « Théories» et l'auteur souligne que «la diversité des candidats potentiels est à la mesure de la crise du sujet de l'émancipation ». Les thématiques abordées sont successivement: le «Système» dont le renouveau des théories de l'impérialisme, les débats autour de l'État-nation; les «Sujets» dont les élaborations des «postféministes », alors que, comme je l'ai déjà indiqué les théories féministes sont contournées, les classes sociales et ce qui est souvent négligé « Les identités conflictuelles ».

Je ne peux juger que la présentation des auteur-e-s que je connais. Les présentations de Razmig Keucheyan reflètent bien leurs préoccupations et leurs analyses. Je ne saurais lui reprocher de ne pas faire une critique plus approfondie de certains discours et d'en rester à une incitation à en savoir un peu plus sur ces auteur-e-s.

Reste que sa lecture de ce qui est nommée «tradition marxiste » souffre des réductions opérées par la seconde et la troisième internationale (je ne sais ce qu'est l'économie marxiste, l'économie socialiste en URSS, le modèle marxiste standard, la persistance du nationalisme comme anomalie du point de vue marxiste, les classes en dehors de leurs relations, etc...).

Je pourrais en dire de même à propos du féminisme et la valorisation des critiques actuelles contournant les théories des féministes, se revendiquant en tant que telles.

Quoiqu'il en soit, au delà des agacements, un livre qui donne un éclairage sympathique sur des pensées critiques universitaires actuelles, tout en soulignant leurs impasses sur les questions 
stratégiques et leurs faibles interactions avec les mouvements politiques et sociaux.

J'aurais aimé que l'auteur approfondisse aussi des possibles différences entre pensées critiques et pensées de l'émancipation. «Une nouvelle théorie critique est une théorie, et non une simple analyse ou explication. Elle réfléchit non seulement sur ce qui est, mais aussi sur ce qui est souhaitable. En cela, elle comporte nécessairement une dimension politique. Sont critiques les théories qui remettent en question l'ordre social existant de façon globale. Les critiques qu'elles formulent ne concernent pas des aspects limités de cet ordre, comme l'instauration d'une taxe sur les transactions financières, ou telle mesure relative à la réforme des retraites. Qu'elles soient radicales ou plus modérées, la dimension "critique" des nouvelles théories critiques réside dans la généralité de leur remise en question du monde social contemporain. »

\section{Didier Epsztajn}

PS : Comme me l'a signalé, une lectrice critique, que je remercie, il est pour le moins incongru que Razmig Keucheyan souligne, entre Walter Benjamin et Carl Schmitt «une similitude des expériences qu'ils ont vécues, à commencer par celle de la République de Weimar dont ils sont issus. »

Il ne saurait exister de parenté (sauf à ne compter pour rien l'intentionnalité), entre Walter Benjamin qui parle du point de vue des vaincus de l'histoire, des groupes opprimés, défaits, discriminés ou oubliés, et Carl Schmitt qui adhère à « l'ennemi commun », justement ceux qui font sens dans le positionnement théorique de Walter Benjamin. 